\title{
The Effects of Maturity and Preservation Method on Nutrient Composition and Digestibility of Master Graze
}

\author{
A. M. Salamone' , A. A. AbuGhazaleh" ${ }^{*}$, and C. Stuemke ${ }^{1}$ \\ 1 Department of Animal Science, Food and Nutrition, Southern Illinois University, Carbondale, IL 62901, USA
}

Received: June 14, 2012 / Accepted: July 12, 2012

\begin{abstract}
The objective of experiment two was to evaluate the effects of maturity and harvest preservation method on Master Graze (MG) nutrient composition and digestibility. The MG was harvested on June 28 (Cut 1; 48 days), July 20 (Cut 2; 69 days), and August 12 (Cut 3; 92 days) and samples were then preserved using three different preservation methods (oven-dried hay (HAY), ensiled (SIL), or freeze dried (FD)) at each maturity. The collected samples were then analyzed for organic matter $(O M)$, crude protein (CP), ether extract (EE), acid detergent fiber (ADF), neutral detergent fiber (NDF) and lignin. The OM content was similar for Cut 2 and Cut 3 and both were higher $(P<0.01)$ than Cut $1(92.4,95.4$ and $95.0 \%$ for cuts 1 to 3 , respectively). The NDF content was highest ( $P$ $<0.05)$ with Cut $3(63.1 \%)$ and was least $(P<0.05)$ with Cut $2(60.1 \%)$. Cut 3 had a higher $(P<0.01)$ lignin content compared to both Cut 1 and Cut 2 (3.5, 3.4 and $4.1 \%$, respectively). Crude protein content was higher $(P<0.01)$ for Cut 1 than Cut 2 and Cut 3 (8.0, 6.0, and $6.0 \%$, respectively). The preservation method did not affect the $\mathrm{CP}$ or lignin content of the MG. The NDF content was highest $(P<0.01)$ with HAY $(65.8 \%)$ and was least $(P<0.01)$ with FD $(58.6 \%)$. The digestibility of the MG was measured under in situ conditions using one cow fitted with a rumen cannula. The ground ovendried hay, ensiled and freeze dried samples were incubated in the rumen for $\mathbf{2 4} \mathrm{h}$ using the mobile nylon bag techniques. The DM digestibility for Cut 1 and Cut 2 were higher $(P<$ 0.01 ) than Cut 3 (70.0, 67.0 and $60.3 \%$, respectively). The NDF digestibility was highest for Cut 1 and decreased ( $P<$ 0.01 ) with maturity $(58.5,51.6$ and $43.8 \%$ for Cuts 1 to 3 , respectively). Similarly, the $\mathrm{CP}$ digestibility was highest for Cut 1 and also decreased $(P<0.01)$ with maturity $(68.3,56.1$
\end{abstract}

*Corresponding author: aabugha@siu.edu and $46.5 \%$ for Cuts 1 to 3 , respectively). The DM and OM digestibility was higher $(P<0.04)$ with the FD in comparison to both HAY and SIL. Digestibility of NDF was not affected (P $>0.05)$ by preservation methods, while the CP digestibility was higher $(P<0.03)$ with the FD $(61.6 \%)$ than the HAY $(51.4 \%)$. In conclusion, the nutrient composition and digestibility of the MG were both affected by stage of the maturity and preservation method. The nutritional quality of MG decreased with advanced maturity and the MG digestibility was higher when FD preservation method was used.

Keywords: Forage, maturity, preservation method, digestibility.

\section{Introduction}

Feeding high-quality forages increases a lactating dairy cow's efficiency and helps reduce feed costs associated with purchased ingredients, especially proteins. Feed intake of forages is influenced by many factors two of which are maturity and/or the preservation method of the forage. The two most influential factors that affect forage quality and utilization are the forage species and forage maturity (Arthington and Brown, 2005). As forage matures greater lignification occurs within the plant cell wall. This increase in lignin concentration in the plant cell wall decreases DM consumption (Moore and Jung, 2001) and forage rate of digestion in the rumen (Beck et al., 2009). The type of preservation method used on a forage effects the nutrient composition of the forage. Whether the forage is ensiled or made into hay, part of the protein is broken down due to the action of plant enzymes in the field after harvest (Verbic et 
al., 1999). Additionally, when forage is preserved as hay, lignification can increase in the cell walls of the plant during the wilting process. The ensiling process also alters the nutrients profile and tertiary structure of ensiled feeds (Kohn and Allen, 1995). Producing high quality forages and large quantities of that forage, is largely dependent on harvesting at the optimum maturity while optimizing the storage/preservation conditions. There has been well-documented evidence that forage's nutrient content (proteins, minerals and vitamins) and digestibility decreases as the plant matures; therefore affecting the animals feed intake and performance. Consequently, the pounds of plant material harvested per acre increases as the plant's maturity increases and the digestibility of the plant decreases. Thus, the optimum harvest date is a compromise between the forage quality and quantity produced.

Recently, a new BMR corn hybrid called Master Graze (MG) was developed by Master's Choice Inc. (Anna, IL, USA). Master Graze is a crop that can be planted and harvested earlier than the rest of the crops and has the potential to make time management in the field more efficient. Master Graze can be planted in early spring when soil temperatures are between $50-55^{\circ} \mathrm{F}$, in comparison to Sorghum Sudan that requires a soil temperature of $60-65^{\circ} \mathrm{F}$. The ability of MG to grow at a lower soil temperature allows fields to be planted five to six weeks earlier than most other crops and then it can be harvested within seven to eight weeks. Although MG may provide alternative forage source to dairy producers, research is needed be evaluated and determine the effect of maturity and the preservation method on the nutritional value of MG. Data on the feeding value of $M G$ silage for ruminants is not available, and currently, no published work has determined the potential effects of maturity and the preservation method on the nutritional value of MG. Therefore, the objective of this study was to evaluate the effects of maturity and harvest preservation method on MG nutrient composition and digestibility.

\section{Materials and Methods}

\section{Sampling}

The MG (Master's Choice, Anna IL) was harvested from a 3.89 hectare (ha) field (Southern Illinois University Carbondale Dairy Farm, Carbondale IL) on June 28 (Cut 1; 48 days), July 20 (Cut 2; 69 days), and August 12 (Cut 3; 92 days) using a hand knife. Harvested samples were then preserved using three different methods (oven-dried hay (HAY), ensiled (SIL), or freeze dried (FD)) at each maturity. For the oven-dried hay preservation method, fresh samples were placed in an oven at $55^{\circ} \mathrm{C}$ for 72 hours, ground through a 2-mm screen using a Wiley mill (Arthur $\mathrm{H}$. Thomas, Philadelphia, PA) and stored at room temperature until analysis. For the silage preservation method, the fresh samples were coarsely chopped by an electric powered silage chopper (The Silver MFG Co., Salem, OH) and then packed into three mini silos (2.62 L) per maturity, made from Polyvinyl Chloride pipe. The samples were then ensiled for 60 days. The silage was then placed in an oven at $55^{\circ} \mathrm{C}$ for 72 hours, ground through a 2-mm screen using a Wiley mill (Arthur H. Thomas, Philadel- phia, PA) and stored at room temperature until analysis. For the freeze dried preservation method, the freshly cut samples were immediately placed in a cooler under ice, transferred to the lab within 30 minutes, and stored at $-80^{\circ} \mathrm{C}$. The frozen samples were then freeze dried using a Genesis 25 SQ Super ES (SP Industries, Gardiner, NY), ground through a 2-mm screen using a Wiley mill (Arthur H. Thomas, Philadelphia, PA) and then stored at -20 OC until analysis until analyzed for DM, OM, CP (LECO FP-528, St. Joseph, MI) and ether extract (ANKOM XT10, Macedon, NY ), ADF, NDF (ANKOM 200 Fiber Analyzer, Macedon, NY) and lignin (Van Soest et al., 1991; AOAC 2000).

\section{Digestibility}

The digestibility was measured under in situ conditions using one cow fitted with a rumen cannula. The cow was fed a mixed diet of $30 \%$ corn silage, $30 \%$ alfalfa hay and $40 \%$ concentrates once daily. The ground oven-dried hay, ensiled, and freeze dried samples were incubated in the rumen for 24 hours using the mobile nylon bag technique. The samples were incubated in $5 \times 10-\mathrm{cm}$ Dacron bags (Ankom Inc., Fairport, NY) that had a $50-\mu \mathrm{m}(S D=5$ ) pore size (Haugen et al., 2006). Samples were run in duplicates over a 2-day period. After incubation, the bags were removed and rinsed in 5-gallon buckets of cold water for a total of six rinses. The bags were then dried in an oven at $55^{\circ} \mathrm{C}$ for $48 \mathrm{~h}$, placed in a desiccator for $3 \mathrm{~h}$ and weighed. The samples were then analyzed for $\mathrm{OM}$, ash, $\mathrm{CP}, \mathrm{EE}$ ADF, NDF and lignin as described previously. The nutrient digestibility were then measured based on disappearance from bags.

\section{Statistical Analysis}

Data for maturity, preservation method and digestibility were analyzed using the MIXED PROC of SAS (SAS Institute Inc., Cary, NC). The statistical model includes maturity, preservation method, maturity $x$ preservation method interaction, sample and residual error. The maturity and preservation method were the fixed effects and the sample was the random effect. Significance was declared at $\mathrm{P}<0.05$.

\section{Results}

The effect of maturity on MG nutrient composition is presented in Figure 1. The OM content (Figure 1 a) was similar for Cut 2 and Cut 3 and both were higher $(P<0.01)$ than Cut 1 (92.4, 95.4 and $95.0 \%$ for Cuts 1 to 3 , respectively). The NDF content (Figure 1b) was highest $(P<0.05)$ with Cut $3(63.1 \%)$ and was least $(P<0.05)$ with Cut $2(60.1 \%)$. Cut 3 had a higher $(P<0.01)$ content of lignin in comparison to both Cut 1 and Cut 2 (3.4, 3.5 and $4.1 \%$ for Cuts 1 to 3, respectively; Figure 1c). Crude protein content was higher $(P<0.01)$ for Cut 1 than Cut 2 and Cut 3 (8.0, 6.0 and $6.0 \%$ for Cuts 1 to 3, respectively; Figure 1d).

The effect of preservation method on MG nutrient composition is presented in Figure 2. The OM content (Figure 2a) was similar for FD and HAY and both were higher $(P<0.04)$ than SIL (94.4, 94.4 and $94.1 \%$ for FD, HAY and SIL, respectively). 

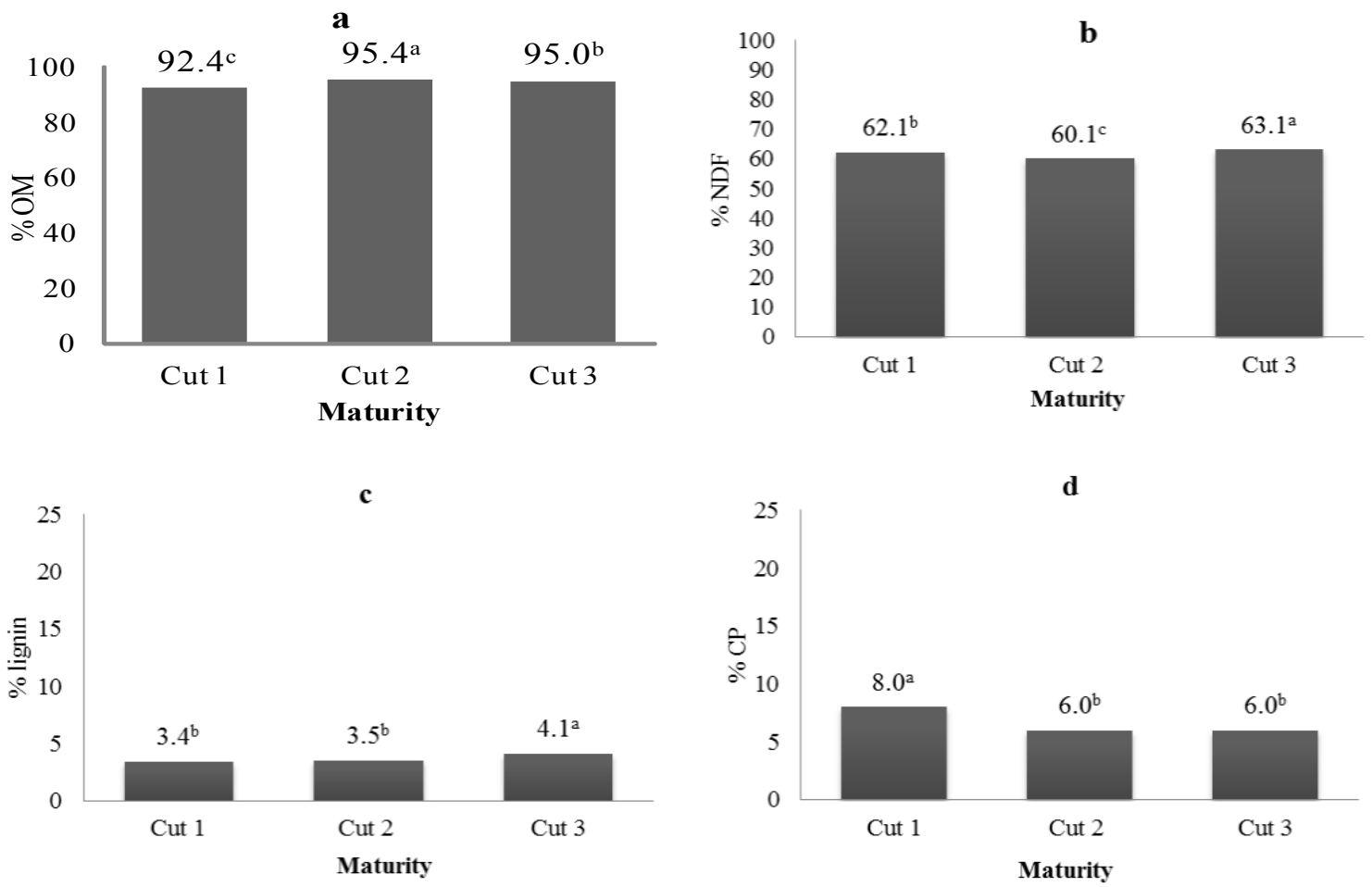

Figure 1. Effect of maturity on the chemcial composition of Master Graze (OM (a), NDF (b), lignin (c) and CP (d)). The mean square error for $O M$ is $0.094, N D F$ is 0.366 , lignin is 0.147 , and CP is 0.309 . a,b,c: columns with different superscripts are statistically different at $\mathrm{P}<0.05$.
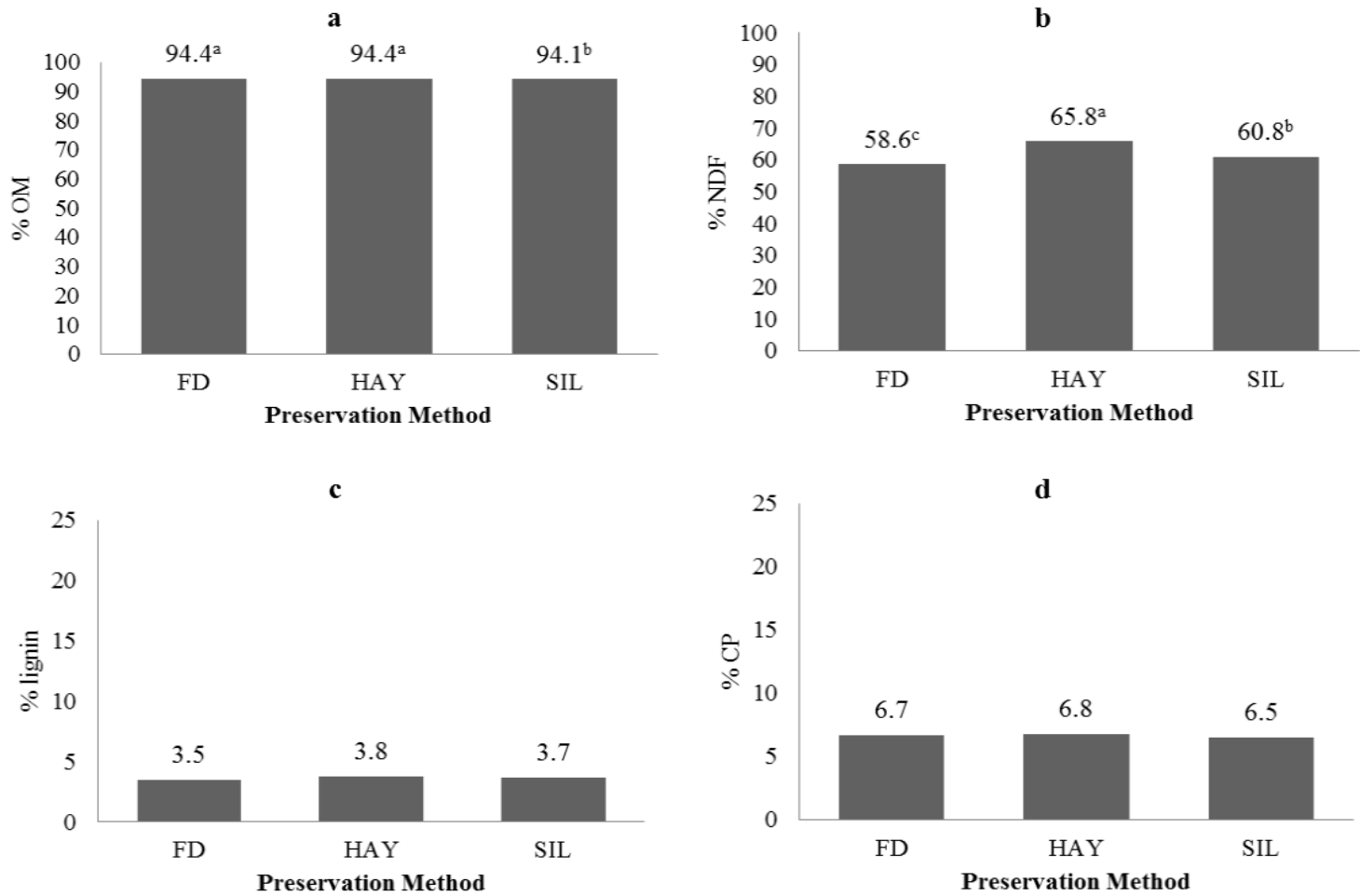

Figure 2. Effect of preservation method on the chemcial composition of Master Graze (OM (a), NDF (b), lignin (c) and $C P(d))$. The mean square error for OM is $0.094, N D F$ is 0.366 , lignin is 0.147 , and CP is 0.309 . a,b,c: columns with different superscripts are statistically different at $P<0.05$. 
a

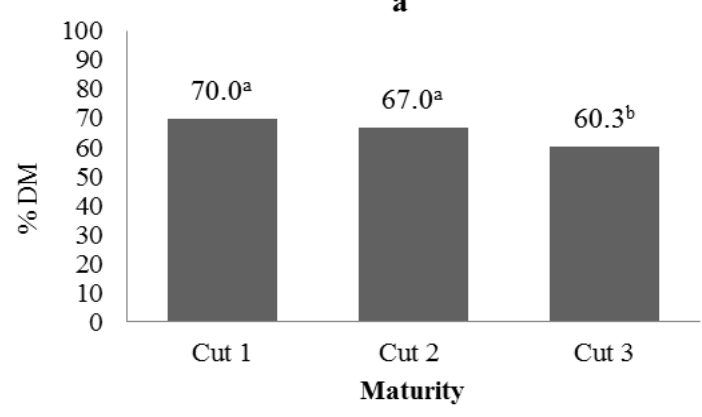

c

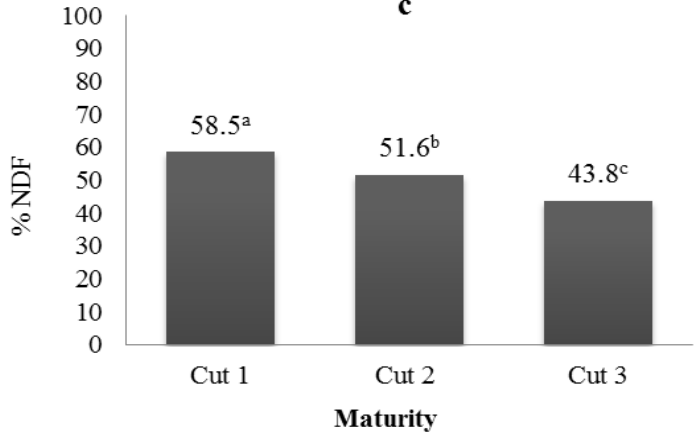

b

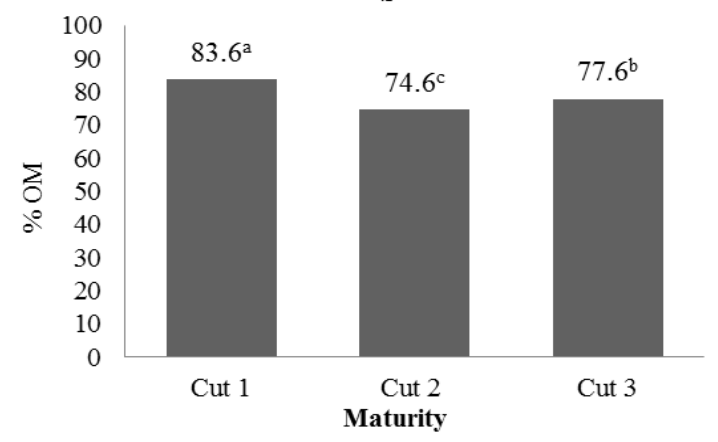

d

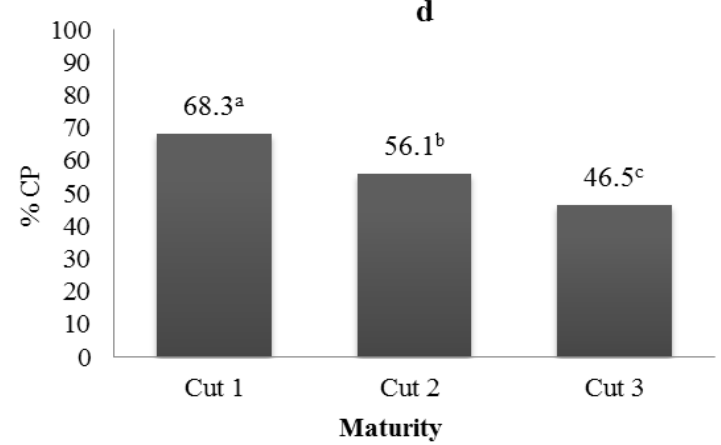

Figure 3. Effect of the stage of maturity on the digestibility of Master Graze DM (a), OM (b), NDF (c) and CP (d). The mean square error of DM is $1.469, \mathrm{OM}$ is $1.044, \mathrm{NDF}$ is $2.304, \mathrm{CP}$ is 3.059 . a,b,c: columns with different superscripts are statistically different at $P<0.05$.

In Figure 2b, the NDF content was highest ( $P<0.01$ ) with HAY $(65.8 \%)$ and was least $(P<0.01)$ with FD $(58.6 \%)$, with SIL $(60.8 \%)$ as an intermediate. The lignin content was not affected $(P>0.05)$ by the preservation method $(3.5,3.8$ and $3.7 \%$ for FD, HAY and SIL, respectively). Preservation method in this study also had no effect $(P>0.05)$ on $C P$ content $(6.7,6.8$ and $6.5 \%$ for FD, HAY and SIL, respectively).

The effect of maturity on MG nutrient digestibility is presented in Figure 3. In Figure 3a, the DM digestibility for Cut 1 and Cut 2 were higher $(P<0.01)$ than Cut $3(70.0,67.0$ and $60.3 \%$ for Cuts 1 to 3, respectively). The $O M$ digestibility (Figure 3b) was highest $(P<0.01)$ for Cut 1 (83.6\%). Interestingly, Cut 3 $(77.6 \%)$ had a higher $(P<0.01)$ digestibility of $O M$ than Cut $2(74.6 \%)$. On the other hand, the NDF digestibility (Figure 3c) was highest for Cut 1 and decreased $(P<0.01)$ with maturity $(58.5,51.6$ and $43.8 \%$ for Cuts 1 to 3 , respectively). Similarly, the $\mathrm{CP}$ digestibility (Figure $3 \mathrm{~d}$ ) was highest with Cut 1 and also decreased $(P<0.01)$ with maturity $(68.3,56.1$ and $46.5 \%$ for Cuts 1 to 3 , respectively).

The effect of the preservation method on MG nutrient digestibility is presented in Figure 4. In figure 4a, the DM digestibility was higher $(P<0.04)$ with the FD preservation method in comparison to both HAY and SIL $(68.3,63.9$ and $65.0 \%$ for FD, HAY and SIL, respectively). Likewise, the OM digestibility was higher $(P<0.01)$ with the FD preservation method in comparison to both HAY and SIL $(81.3,76.4$ and $78.1 \%$ for FD, HAY and SIL, respectively). Digestibility of NDF was not affected ( $P>0.05$ ) by preservation method $(51.1,52.0$ and 50.7 for FD, HAY and
SIL, respectively) while the CP digestibility was higher $(P<0.03)$ with the FD $(61.6 \%)$ than the HAY $(51.4 \%)$.

The effects of preservation method on the chemical composition of the MG at each cut are presented in Table 1. The NDF content was consistently higher $(P<0.05)$ in all cuts with the HAY and was least with the FD, except in CUT 3 where NDF content was higher $(P<0.05)$ with the FD than the SIL. The ADF content was also consistently lower $(P<0.05)$ with the FD compared to the HAY and SIL, except in CUT 3 where ADF content tended (P $<0.09$ ) to be lower with the FD when compared to the SIL. Except for CUT 1, the lignin content was lower $(P<0.05)$ with the FD compared to the HAY and SIL. Additionally, the lignin content was not different $(P>0.05)$ between the HAY and SIL across all cuts. The CP content was not affected $(P>0.05)$ by preservation method in CUT 2 and CUT 3. However, in CUT 1 CP content was higher $(P<0.05)$ with the FD and HAY compared to the SIL.

The effects of preservation method on the nutrients digestibility of MG at each cut are presented in Table 2. The DM and OM digestibilities were different $(P<0.05)$ between preservation methods only in Cut 2, with digestibilities for both being higher $(P<0.04)$ with the FD than the HAY and SIL. There were no differences $(P>0.05)$ in the NDF digestibility between the three preservation methods across the three cuts. There were also no differences $(P>0.05)$ in the $C P$ digestibility between the three preservation methods in Cut 1 . However in Cut 2, the CP digestibility was higher $(P<0.04)$ with the FD $(65.2 \%)$ in comparison to the HAY (52.1\%) and SIL (51.0\%). In Cut 3, the CP digestibility was higher $(P<0.03)$ with the FD $(49.5 \%)$ and SIL $(53.9 \%)$ 
$\mathbf{a}$

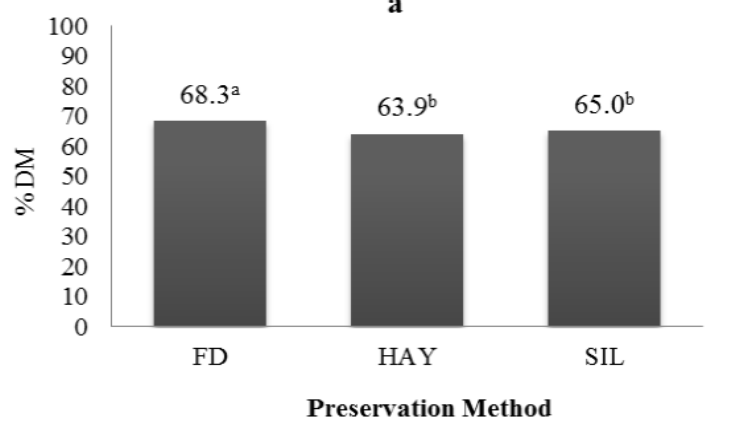

c

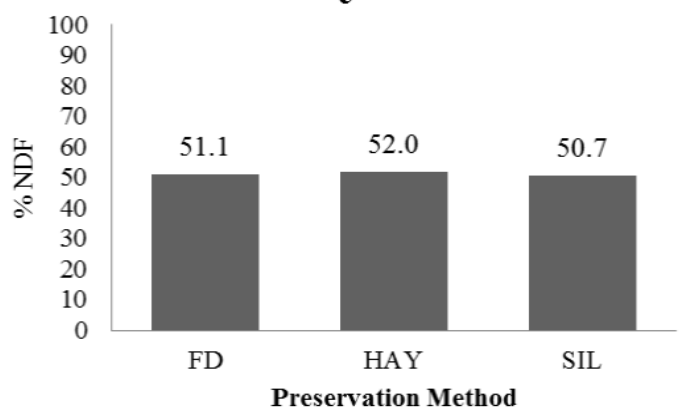

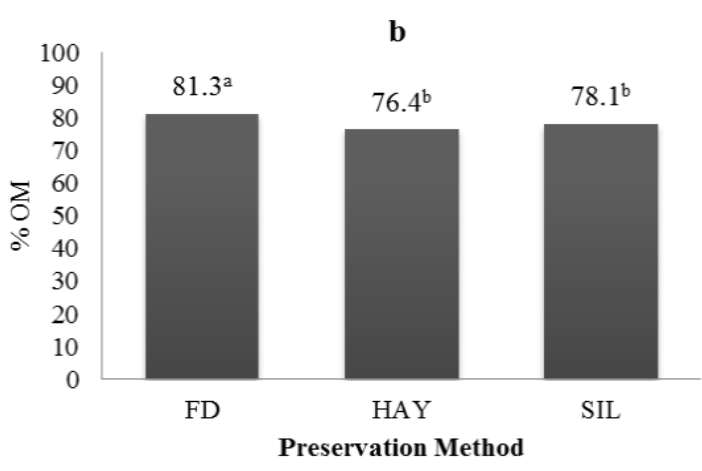

d

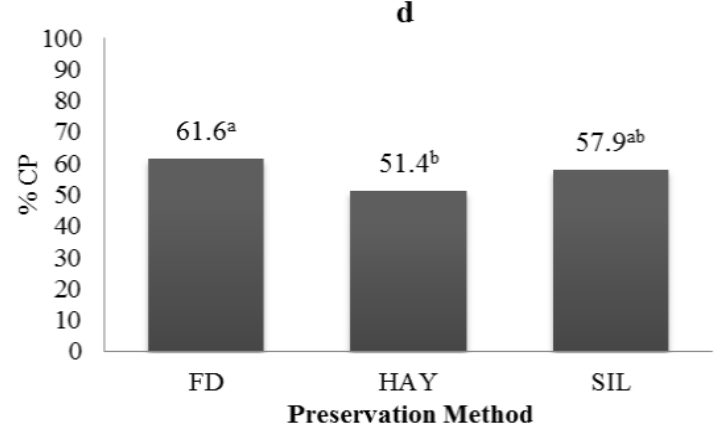

Figure 4. Effect of preservation method on digestibility of Master Graze DM (a), OM (b), NDF (c), CP (d). The mean square error of $D M$ is $1.469, \mathrm{OM}$ is $1.044, \mathrm{NDF}$ is $2.304, \mathrm{CP}$ is 3.059 . a,b,c: columns with different superscripts are statistically different at $\mathrm{P}<0.05$.

Table 1. The effect of the stage of maturity and the preservation method on the chemical composition of Master Graze.

\begin{tabular}{|c|c|c|c|c|c|c|c|c|c|c|c|c|c|}
\hline & \multicolumn{3}{|c|}{ Cut-1 ${ }^{1}$} & \multicolumn{3}{|c|}{ Cut-2 $^{2}$} & \multicolumn{3}{|c|}{ Cut-3 $^{3}$} & \multirow[b]{2}{*}{ MSE } & \multicolumn{3}{|c|}{$P$-value } \\
\hline & FD $^{4}$ & HAY $^{5}$ & SIL $^{6}$ & FD & HAY & SIL & FD & HAY & SIL & & CUT $^{7}$ & PRES $^{8}$ & CUT*PRES \\
\hline$O M^{10}$ & $92.6^{a}$ & $92.7^{a}$ & $91.9^{b}$ & $95.5^{a}$ & $95.1^{b}$ & $95.7^{a}$ & $94.9^{b}$ & $95.5^{a}$ & $94.6^{c}$ & 0.16 & 0.01 & 0.02 & 0.01 \\
\hline NDF $^{11}$ & $58.3^{c}$ & $65.9^{a}$ & $62.1^{\mathrm{b}}$ & $55.3^{c}$ & $63.1^{\mathrm{a}}$ & $61.8^{b}$ & $62.3^{b}$ & $68.6^{a}$ & $58.4^{c}$ & 0.64 & 0.01 & 0.01 & 0.01 \\
\hline lignin & $3.8^{a}$ & $3.5^{\mathrm{ab}}$ & $3.1^{\mathrm{b}}$ & $2.9^{b}$ & $3.8^{a}$ & $3.8^{a}$ & $3.8^{b}$ & $4.1^{a b}$ & $4.4^{\mathrm{a}}$ & 0.24 & 0.01 & 0.18 & 0.01 \\
\hline $\mathrm{CP}^{13}$ & $8.5^{\mathrm{a}}$ & $8.4^{\mathrm{a}}$ & $7.1^{\mathrm{b}}$ & 6.0 & 6.3 & 5.7 & 5.7 & 5.7 & 6.7 & 0.54 & 0.01 & 0.62 & 0.07 \\
\hline
\end{tabular}

${ }^{1}$ Cut- $1=$ Master Graze silage harvested at 48 days

${ }^{2}$ Cut- 2 = Master Graze silage harvested at 69 days

${ }^{3}$ Cut-3 $=$ Master Graze silage harvested at 92 days

${ }^{4} \mathrm{FD}=$ freeze dried

${ }^{5} \mathrm{HAY}=$ oven dried

${ }^{\circ} \mathrm{SIL}=$ silage

${ }^{7} \mathrm{CUT}=$ stage of maturity

${ }^{8} \mathrm{PRES}=$ preservation method

'CUT*PRES= interaction between stage of maturity and the preservation method

${ }^{10} \mathrm{OM}=$ organic matter

${ }^{11} \mathrm{NDF}=$ neutral detergent fiber

${ }^{12} \mathrm{ADF}=$ acid detergent fiber

${ }^{13} \mathrm{CP}=$ crude prote in

$a, b, c$ : rows with different superscripts are statistically different at $P<0.05$.

in comparison to the HAY $(36.2 \%)$.

\section{Discussion}

The OM content in CUT 1 was lower than both CUT 2 and CUT 3. The NDF content of the MG was highest in CUT 3 which was expected with the later maturity. Similarly, in studies done by Rinne et al. (2002), Arthington and Brown (2005), and Beck et al. (2007) the NDF content increased as forage maturity increased. In studies done by Snyman and Joubert (1996), the NDF content remained constant as the maturity increased. Whereas, Black et al. (1980) observed that the NDF content decreased as the maturity increased in the sorghum silage. The lignin content in the MG was also highest in CUT 3, due to the later maturity and 
Table 2. The effect of stage of maturity and preservation method on the nutrient digestibility of Master Graze.

\begin{tabular}{|c|c|c|c|c|c|c|c|c|c|c|c|c|c|}
\hline & \multicolumn{3}{|c|}{ Cut-1 $^{1}$} & \multicolumn{3}{|c|}{ Cut-2 $^{2}$} & \multicolumn{3}{|c|}{ Cut-3 $^{3}$} & \multirow[b]{2}{*}{ MSE } & \multicolumn{3}{|c|}{ P-value } \\
\hline & $\mathrm{FD}^{4}$ & HAY ${ }^{5}$ & $\mathrm{SIL}^{6}$ & FD & HAY & SIL & FD & HAY & SIL & & CUT $^{7}$ & PRES $^{8}$ & CUT*PRES $^{9}$ \\
\hline $\mathrm{DM}^{10}$ & 71.9 & 67.3 & 70.8 & $72.6^{a}$ & $65.5^{b}$ & $62.7^{\mathrm{b}}$ & 60.3 & 59.1 & 61.6 & 2.55 & 0.01 & 0.04 & 0.09 \\
\hline$O M^{11}$ & 83.5 & 82.8 & 84.5 & $80.4^{a}$ & $73.1^{\mathrm{b}}$ & $70.1^{\mathrm{b}}$ & 79.8 & 73.4 & 79.7 & 1.81 & 0.01 & 0.01 & 0.06 \\
\hline $\mathrm{NDF}^{12}$ & 58.4 & 56.9 & 60.2 & 54.9 & 52.1 & 47.7 & 40.0 & 47.0 & 44.3 & 3.99 & 0.01 & 0.85 & 0.24 \\
\hline $\mathrm{CP}^{13}$ & 70.0 & 65.9 & 68.9 & $65.2^{\mathrm{a}}$ & $52.2^{b}$ & $51.0^{\mathrm{b}}$ & $49.5^{a}$ & $36.2^{\mathrm{b}}$ & $53.9^{a}$ & 5.29 & 0.01 & 0.03 & 0.12 \\
\hline
\end{tabular}

${ }^{1}$ Cut-1 $=$ Master Graze silage harvested at 48 days

${ }^{2}$ Cut-2 = Master Graze silage harvested at 69 days

${ }^{3}$ Cut-3= Master Graze silage harvested at 92 days

${ }^{4} \mathrm{FD}=$ freeze dried

${ }^{5} \mathrm{HAY}=$ oven dried

${ }^{6} \mathrm{SIL}=$ silage

${ }^{7} \mathrm{CUT}=$ stage of maturity

${ }^{8} \mathrm{PRES}=$ preservation method

${ }^{9}$ CUT*PRES $=$ interaction between stage of maturity and the preservation method

${ }^{10} \mathrm{DM}=$ dry matter

${ }^{11} \mathrm{OM}=$ organic matter

${ }^{12} \mathrm{NDF}=$ neutral detergent fiber

${ }^{13} \mathrm{CP}=$ crude protein

a,b: rows with different superscripts are statistically different at $P<0.05$.

more lignin formation in the cell wall of the plant. As expected, the CP content of the MG was highest in CUT 1 in comparison to both CUT 2 and CUT 3. In other studies, the CP content of the forages also deceased with maturity, mostly as a result of a higher stem to leaf ratio (Ademosum et al., 1968; Black et al., 1980; Snyman and Joubert 1995; Rinne et al., 2002, Arthington and Brown, 2005; Beck et al., 2007; Beck et al., 2009).

The OM content due to the preservation method, was similar in the FD and the HAY, but lower in the SIL. This effect could have resulted from the respiration of other forage components in the samples during ensiling (Nelson and Satter, 1992; Kohn and Allen, 1995). The NDF content of the MG was highest in the HAY and lowest in the FD, possibly due to soluble carbohydrates being incorporated into the NDF component via the Maillard reactions during drying. Other studies (Snyman and Joubert, 1995; Beck et al., 2009) have also reported higher NDF content in hay than in silage. The lower NDF content in the SIL than in the HAY was presumably because of soluble carbohydrates and hemicelluloses hydrolysis during the ensiling process. Similar results were also reported by Nelson and Satter (1992), Kohn and Allen (1995), and Snyman and Joubert (1995). The preservation methods in this study had no effects on MG lignin and CP content, which is inconsistent with the findings of Kohn and Allen (1995), who reported higher CP and lignin contents in the silage and hay in comparison to the freeze dried samples. In studies done by Nelson and Satter (1992) and Snyman and Joubert (1995), the CP content was lower in hay than in silage and authors attributed that to leaf losses during the hay making. In this study, leaf loss during hay making was unlikely, as samples were dried in an oven using deep pans to avoid losing any of the samples.

The apparent DM and OM digestibility was higher in CUT 1 than CUT 3. The lower DM and OM digestibility with CUT 3 was expected, as these samples had higher lignin and NDF content. The DM digestibility also decreased with advanced maturity in studies by Ademosum et al. (1968) with sorghum-sudangrass and Black et al. (1980) with sorghum silage. Arthington and Brown (2005) also reported lower OM digestibility with advanced maturity in Bermudagrass and Stargrass forages. Consistent with other studies (Black et al., 1980; Kohn and Satter, 1995; Beck et al., 2009), advanced maturity in the present study resulted in lower apparent NDF and CP digestibility. Rinne et al. (2002) also reported lower NDF and CP digestibility with advanced maturity of grass silage. The higher lignin content in CUT 3 may have limited rumen microbe's access to the cell content and therefore reduced $M G$ digestibility.

The digestibility of DM and OM was similar in HAY and SIL, but higher in FD. Snyman and Joubert (1995) reported no effects of ensiling on DM digestibility and a lower digestibility of $D M$ in the hay than the fresh forage sorghum. The lower digestibility of DM and OM with the HAY and SIL relative to FD may due to lower NDF content in FD samples and/or Maillard reaction during drying or fermentation process. The higher digestibility of CP with the FD samples further supports the Miallard reaction effects on OM and CP digestibility in SIL and HAY. The higher CP digestibility with SIL than HAY was consistent with the findings of Verbic et al. (1999) and Kohn and Allen (1995) who reported silages having higher CP digestibility than hay forages. The higher digestibility of $\mathrm{CP}$ in silages was presumably due to the greater soluble protein content in silages and/or protein degradation during wilting.

\section{Conclusion}

The nutrient composition and apparent ruminal digestibility of MG were both affected by stage of maturity and preservation method of the forage. As seen in most forages, the nutritional quality of $M G$ decreased with advanced maturity, which therefore decreased the digestibility of the forage. This study 
also showed that the FD was a better method than the HAY and SIL to preserve MG as the FD samples had consistently higher digestibility.

\section{References}

Ademosum AA, BR Baumgardt, and JM. Scholl (1968) Evaluation of a sorghum-sudangrass hybrid at varying stages of maturity on the basis of intake, digestibility and chemical composition. J. Anim. Sci. 27:818-823.

AOAC (2000) Official methods of analysis. 17th ed. Assoc. Offical Analytical Chemists. Gaithersburg, MD.

Arthington, JD, and WF Brown (2005) Estimation of feeding value of four tropical forage species at two stages of maturity. J. Anim. Sci. 83:1726-1731.

Beck PA, S Hutchison, SA Gunter, TC Losi, CB Stewart, PK Capps, and JM Phillips (2007) Chemical composition and in situ dry matter and fiber disappearance of sorghum $x$ Sudangrass hybrids. J. Anim. Sci. 85:545-555.

Beck PA, CB Stewart, HC Gray, JL Smith, and SA Gunter (2009) Effect of wheat forage maturity and preservation method on forage chemical composition and performance of growing calves fed mixed diets. J. Anim. Sci. 87:4133-4142

Black JR, LO Ely, ME McCullough, and EM Sudweeks (1980) Effects of stage of maturity and silage additives upon the yield of gross and digestible energy in sorghum silage. J. Anim. Sci. 50:617-624.

Haugen HL, SK Ivan, JC MacDonald, and T J Klopfenstein (2006) Determination of undegradable intake protein digestibility of forages using the mobile nylon bag technique. J. Anim. Sci. 84:886-893.

Kohn RA, and MS Allen (1995) Effect of plant maturity and preservation method on in vitro protein degradation of forages. J. Dairy Sci. 78:1544-1551.

Moore KJ, and HG Jung (2001) Lignin and fiber digestion. J. Range Manage. 54:420-430.

Nelson WF, and LD Satter (1992) Impact of stage of maturity and method of preservation of alfalfa on digestion in lactating dairy cows. J. Dairy Sci. 75:1571-1580.

Rinne M, P Huhtanen, and S Jaakkola (2002) Digestive processes of dairy cows fed silages harvested at four stages of grass maturity. J. Anim. Sci. 80:1986-1998

Snyman LD, and HW Joubert (1996) Effect of maturity stage and method of preservation on the yield and quality of forage sorghum. Anim. Feed Sci. Technol. 57:63-73.

Verbic J, ER Orskov, J Zgajnar, XB Chen, and V Znidarsic-Pongrac (1999) The effect of method of forage preservation on the degradability and microbial protein synthesis in the rumen. Anim. Feed Sci. Technol. 82:195-212.

Van Soest PJ, JB Robertson, and BA Lewis (1991) Methods for dietary fiber, neutral detergent fiber, and nonstarch polysaccharides in reflection to animal production. J. Dairy Sci. 74:3583-3597. 